\title{
La sana crítica y el olvido de las reglas de sana crítica*
}

\author{
Johann Benfeld Escobar**
}

\begin{abstract}
RESUMEN
Este artículo afirma que originalmente la idea de sana critica se encontraba indisolublemente ligada a la noción de juicios razonables en materia de ponderación de la prueba. Estos juicios de buen criterio o de sana crítica, a su vez, dotaban de cierta autonomía al método de ponderación establecido primero en la Ley de Enjuiciamiento Civil española de 1855 y luego en su sucesora de 1881. Sin embargo, la falta de una reflexión y sistematización de las referidas reglas de sana crítica muy pronto llevó a la doctrina a independizar el método de ponderación de sus criterios propios, con lo que la sana crítica devino en una variación más de los sistemas de libre valoración de la prueba, perdiendo así, en buena medida, su importancia científica y práctica.
\end{abstract}

Sana crítica - reglas de la sana crítica - ponderación de la prueba

\section{The sound criticism and the oblivion of the rules of sound critism}

\begin{abstract}
This article states that, originally, the idea of sound criticism was inextricably linked to the notion of reasonable judgments in weight of evidence. These judgments of sound criticism, in turn, gave autonomy to the method, first, established in the Law of Spanish Civil Procedure of 1855 and, then, in its successor of 1881. However, the lack of reflection and systematization of the rules of sound criticism led the doctrine to make independent the method of its own criteria, becoming the sound criticism a further variation of the free-evaluation systems. In consequence, the rules lost their scientific and practical importance.
\end{abstract}

Sound criticism - rules of sound criticism - weight of evidence

* Este artículo forma parte del proyecto Fondecyt de iniciación No $\mathrm{N}^{\circ} 11160046$, titulado "Formulación de un concepto jurídico alternativo de reglas de sana crítica en materia probatoria y sistematización de los criterios y de las reglas particulares a él asociadas", del que el autor es investigador principal. Un borrador de este trabajo ha sido leído y discutido por los profesores Eduardo Aldunate y Jorge Larroucau. A ellos pues mi más sincero agradecimiento.

** Licenciado en Filosofía, Universidad Católica de Valparaíso. Licenciado en Ciencias Jurídicas, Pontificia Universidad Católica de Valparaíso. Doctor en Derecho, Universidad de Salamanca, España. Profesor de Teoría y Filosofía del Derecho, Pontificia Universidad Católica de Valparaíso. Correo electrónico: johann.benfeld@pucv.cl

Artículo recibido el 16.1.2017 y aceptado para su publicación en este número el 5.1.2018. 


\section{INTRODUCCIÓN}

U

no de los primeros en advertir la novedad del sistema de ponderación de la prueba de la sana crítica con relación a los sistemas de tarifa legal y de íntima convicción fue F. Gorphe. A él le pareció que la modificación contenida en el artículo 659 de la Ley de Enjuiciamiento Civil española de 1881, que prescribía la forma de valorar la prueba testimonial de acuerdo con la sana crítica, introducía una prometedora y nueva alternativa a los sistemas tasados y de íntima convicción ${ }^{1}$. Años más tarde, E. Couture ahondaría aún más en estas ideas al señalar que la sana crítica configura una categoría intermedia entre la prueba legal y la libre convicción. Sin la excesiva rigidez de la primera y sin la excesiva incertidumbre de la última, configura una feliz fórmula, elogiada alguna vez por la doctrina, de regular la actividad intelectual del juez frente a la prueba ${ }^{2}$. Fue probablemente el propio Couture quien terminó por precisar, por lo menos en el contexto latinoamericano, el concepto canónico de sana crítica que, a partir de sus escritos, quedó indisolublemente ligado a los principios de la lógica y las máximas de la experiencia, presentándose como una tercera vía metodológica de ponderación de la prueba judicial ${ }^{3}$.

Con el tiempo, y probablemente debido a la incapacidad de la doctrina por precisar, por una parte, las ideas que en teoría dotaban de especialidad al método de la sana crítica

${ }^{1}$ Gorphe, F., La Crítica del Testimonio, Instituto Editorial Reus, Madrid, 1940, pp. 31-32. Resulta interesante que Gorphe se haya remitido al artículo 659 de la Ley de Enjuiciamiento Civil española de 1881, y no al artículo 317 de la primitiva ley de enjuiciamiento de 1855, que fue el que, por vez primera en materia procesal civil, introdujo en España la idea de "sana crítica" a propósito de la ponderación de la prueba testimonial.

${ }^{2}$ Couture, E., Fundamentos del Derecho Procesal Civil, Tercera edición, Roque de Palma Editor, Buenos Aires, 1958 , p. 270.

${ }^{3}$ La influencia de Couture en este sentido es indiscutible, en tal sentido véase: en Uruguay, Valentín, Gabriel, "La prueba y la sentencia: algunas reflexiones sobre la regla de la carga de la prueba", en Revista de Derecho, Segunda época, Año 9. N 10, diciembre 2014, p. 254. En nuestro medio nacional, Cerda San Martín, Rodrigo, Valoración de la prueba. Sana crítica, Librotecnia, Santiago, 2008; Laso Cordero, Jaime, "Lógica y sana crítica", en Revista Chilena de Derecho, No 36, 1, 2009; Coloma Correa, Rodrigo, "La caída del argumento de autoridad y el ascenso de la sana crítica" en Revista de Derecho (Valdivia), Vol. XXV, No 2, 2012; Coloma Correa, Rodrigo, "Realmente importa la sana crítica", en Revista Chilena de Derecho, Vol. 39, No 3, 2012; Coloma, Rodrigo y Agüero, Claudio, "Fragmento de un imaginario judicial de la sana crítica", en Ius et Praxis, 20, N 2, 2014; Coloma, Rodrigo y Agüero, Claudio, "Lógica, ciencia y experiencia en la valoración de la prueba", en Revista Chilena de Derecho, Vol. 41, No 2, 2014; Lepin Molina, Cristian, "Breve estudio sobre la sana crítica”, en Gaceta Jurídica, n ³19, 2007; López Díaz, Carlos, "Apreciación de la prueba por la sana crítica y procedencia del recurso de casación en el fondo en los procesos ante los tribunales de familia”, en Gaceta Jurídica, No 294, 2004; Maturana Baeza, Javier, Sana crítica, Ed. Thomson Reuters, Santiago, 2014. En el contexto latinoamericano, García, Lyda y Acuña, Máximo, "Elementos de la sana crítica en el proceso civil”, en Justicia, No. 26, diciembre 2014, pp. 44-57. Finalmente, a nivel iberoamericano José L. Vázquez Sotelo precisa que algunas de las ideas de Couture influyeron también en las proyecciones de lege ferenda que tuvo la LEC española (con posteioridad a 1881) y otros cuerpos normativos iberoamericanos relacionadas con la falta de idoneidad del sistema de íntima convicción (ponderación libre) de carácter voluntarista y propio de los procesos de valoración mediante jurados populares (vid. Vázquez, José, "Los principios del proceso civil, en Responsa Iurisperitorum Digesta, Eduardo A. Fabián Caparrón editor, Ediciones Universidad de Salamanca, Salamanca, 2000, pp. 111-156). 
y, por otra, de excluir tales ideas de los otros sistemas de ponderación, los teóricos del derecho comenzaron a preguntarse si efectivamente la sana crítica constituía un sistema diverso al de la libre valoración de la prueba. En otros términos, los partidarios de la teoría de la sana crítica no fueron capaces de precisar en qué sentido los principios de la lógica y las máximas de la experiencia se podían tornar operativos a propósito de la sana crítica. Además, tampoco se advertía ninguna razón para pensar que en los otros sistemas de ponderación de la prueba (con excepción, tal vez, de la íntima convicción francesa referida a jurados populares) los principios de la lógica y las máximas de la experiencia no tuviesen cabida.

Probablemente debido a lo anterior, no todos los autores han atribuido a la sana crítica la importancia y novedad que primero Gorphe y luego Couture pretendían. En tal dirección, Leo Rosenberg en su famoso Tratado de Derecho Procesal Civil de 1951, al momento de analizar los regímenes de ponderación de la prueba, solo distingue entre el sistema de prueba tasada propio del proceso canónico común y el sistema de libre ponderación de la prueba (freiebeweiswürdigung), característico del sistema francés y alemán de su época. De acuerdo con este último el juez (el colegio mediante decisión de mayoría) resuelve sobre esto y, en particular, sobre el valor probatorio del medio de prueba presentado, con completa consideración de todas las circunstancias extraídas mediante el debate o una posible recepción de la prueba, basándose en su experiencia de vida y en el conocimiento de los hombres y de acuerdo con la libre convicción; pero debe indicar en la sentencia sus fundamentos para su propia seguridad, y con el fin del examen en la instancia superior ${ }^{4}$. En Italia, MicheleTaruffo tampoco concede a la sana crítica una fisonomía propia en cuanto sistema de ponderación de la prueba, y no duda en equipararla al sistema de libre valoración (prudente apprezzamento). Eso sí, para Taruffo el sistema de libre valoración de la prueba admite diversas modalidades de implementación. En el caso español el principio se estipula en disposiciones que regulan medios de prueba específicos, como es el caso, por ejemplo, de la referencia a las reglas de la sana crítica como estándares para la valoración de varias clases de pruebas incluidas en los artículos 316.2, 348 y 347 de la Ley de Enjuiciamiento Civil española, pero la pretensión es que el principio opere como criterio general de valoración de la prueba $a^{5}$. En España, Jordi Nieva ha llegado a la misma conclusión que los autores anteriores, señalando que aquello que se deduce de la "sana crítica" no difiere en absoluto de lo que pretende la intime conviction o la Freibeweiswürdigung. Pudiendo concluir, llegados a este punto, que las iniciales enseñanzas de Beccaria y la liberación en la valoración de la prueba inspirada con gran difusión por Blackstone y Bentham, finalmente tuvieron bastante éxito en toda Europa ${ }^{6}$. En nuestro país ${ }^{7}$, a su vez, Javier

${ }^{4}$ Rosenberg, L., Derecho Procesal Civil Tomo II, Ediciones Jurídicas Europa América, Buenos Aires, 1955, p. 206.

5 Taruffo, M., La Prueba, Marcial Pons, Buenos Aires, 2008, p. 135.

${ }^{6}$ Nieva, J., La valoración de la Prueba, Marcial Pons, Madrid, 2010, pp. 89-90.

${ }^{7}$ Aun cuando en los últimos años el tema de la sana crítica ha recibido por parte de la doctrina nacional una mayor atención, todavía es posible advertir un conjunto significativo de vacíos teóricos que han impedido una comprensión acabada a la institución. Solo a modo ejemplar, de momento no se ha logrado dilucidar epistémicamente si la sana crítica constituye una suerte de estándar probatorio o la forma misma que ha de 
Maturana, en su voluminosa monografía titulada simplemente Sana Crítica, tampoco concede a la misma un estatuto absolutamente independiente de la libre ponderación, al afirmar que la sana crítica es una alternativa de sistema de libre valoración en que (...) la discrecionalidad de las valoraciones y de las elecciones puede no equivaler a una irreductible vaguedad o incertidumbre en la decisión y la libertad de la convicción puede estar guiada por criterios racionales. Pero ello no implica que se llegue a conclusiones necesarias ${ }^{8}$.

De acuerdo con los autores que acabamos de citar solo existen dos sistemas de ponderación de la prueba judicial: el de libre valoración y el de tarifa legal. En el primero el juez no está obligado a ponderar el medio probatorio conforme con un criterio previamente establecido por el legislador. Y, en su versión pura, ni siquiera está limitado a un conjunto preestablecido de medios probatorios particulares. En el segundo, por el contrario, el juez debe, por una parte, limitarse a los medios probatorios establecidos previamente para cada procedimiento y, por otra parte, ponderar cada medio de prueba en particular y comparativamente de acuerdo con un sistema de reglas previamente establecido en la ley9 9 . Por cierto, en uno y otro caso podrá el juez emplear los principios

asumir el razonamiento de ponderación. En efecto, un razonamiento puede ser bastante ilógico o contrafáctico y sin embargo arribar a conclusiones lógicas y empíricamente consistentes. De modo tal que alguien podría sostener que todo testigo dice la verdad, Juan vende fruta; el testigo Juan dice la verdad. El entimema Todo $\mathrm{M}$ es S; todo $\mathrm{P}$ es $\mathrm{S}$, sigue siendo lógico sin perjuicio de que la premisa menor Juan vende fruta no forma parte del razonamiento. La diferencia es importante toda vez que los márgenes de discrecionalidad varían significativamente dependiendo de si se entiende a la sana crítica como un estándar probatorio (art. 297 Código Procesal Penal) o una condición del razonamiento en su conjunto, más allá de las conclusiones (art. 456, Código del trabajo). Asimismo, tampoco ha reparado la doctrina, con la precisión científica requerida, en la forma en que los principios de derecho sustantivo alteran las exigencias de la sana crítica. En otras palabras, no es lo mismo apreciar libremente la prueba en sede criminal (por ejemplo, bajo la idea de presunción de inocencia) que en sede labora (por ejemplo, bajo la idea del principio protrabajador). Esto que podría denominarse la cuestión de la modulación de la sana crítica, al igual que otros tantos problemas asociados a ella, tampoco ha recibido la atención que merece.

${ }^{8}$ Maturana, J., Op. cit., 2014, p. 111.

${ }^{9}$ Obviamente entre los sistemas libre y tasado de ponderación de la prueba en sus estados puros es posible percibir una gran cantidad de variaciones y combinaciones. Para un estudio respecto de estos sistemas se puede consultar a Mittermeier, C. J. A., Tratado de la Prueba en Materia Criminal, Revista de Legislación, Madrid, 1837, pp. 95-117. De manera muy clara Mittermeir distingue en su tratado los sistemas de ponderación de prueba legal de los de libre ponderación (especialmente el sistema de jurados). A propósito del sistema de libre valoración (referido a jurados) discierne este autor de manera documentada el diferente horizonte intelectual que orienta la ponderación del jurado en el sistema anglosajón, con una notoria influencia de criterios racionales preestablecidos del sistema de la íntima convicción francesa, absolutamente libre y propensa a la arbitrariedad. En tal dirección escribe Mittermeier que recorriendo los escritos de Starkie, de Philips, de Bentham, se ve que todos estos autores adoptan reglas de pruebas, esencialmente parecidas a las de las leyes alemanas, la única diferencia que las distingue es que éstas tienen un carácter absoluto; que la confesión, por ejemplo, no puede hacer prueba completa, sino cuando reúne tales o cuales condiciones, mientras que en Inglaterra estas misma reglas no son casi siempre otra cosa que una especie de miras que señalan la senda que debe seguir el jurado (Mitermeier, op. cit., p. 104). Las reflexiones de Mittermeier son importantes para el propósito de este trabajo en dos direcciones. La racionalidad, coherencia lógica y aplicación de las máximas de la experiencia se pueden verificar en sistemas de tarifa legal o de libre valoración de la prueba. El sistema de ponderación de la crítica racional, dentro del modelo de Mittermeier se aproximaría al sistema inglés y no al francés, con la particularidad de preferir la figura de un juez profesional a la de los jurados populares. 
de la lógica, las máximas de la experiencia y los conocimientos científicamente afianzados (ya como una exigencia legal, como ocurre en el régimen de libre ponderación, ya porque los referidos principios, máximas y conocimientos se encuentran, muchas veces, integrados en la propia ley probatoria, como acontece en el régimen de tarifa legal bajomedieval). Por estas razones, no se justifica, metodológicamente hablando, insistir en que la sana crítica constituiría una tercera vía allende la prueba tasada y libre al exigir un compromiso racional del juez (coherencia lógica, experiencia común y conocimientos científicos), pues es fácil advertir que este compromiso racional es exigible en todo sistema probatorio racionalmente establecido. Sin embargo, de este razonamiento no se sigue inmediatamente, como parecen concluir los autores precedentes, que la sana crítica sea simplemente el nombre con que la doctrina procesal española designa al sistema de libre ponderación de la prueba.

De hecho, el propio Nieva, sin detenerse mucho en ello, advierte algunas características propias del sistema de ponderación de la sana crítica que podrían explicar de mejor manera su naturaleza sin necesidad de disolverla en la idea de libre ponderación de la prueba. En efecto, comentando las primeras interpretaciones que recibió el artículo 317 de la Ley de Enjuiciamiento Civil de 1855 (que establecía que la prueba testimonial sería apreciada por el sentenciador conforme a la sana crítica), Nieva señala que gran parte de la doctrina española de la época pensó que el referido artículo no derogaba del todo la Ley de Partidas (que contenía un conjunto de reglas de buen criterio), es decir, dichos autores insistieron en la vigencia limitada de las reglas contenidas en las Partidas. Aunque ello no se produjera por facilitar la valoración de la prueba, sino por un evidente conservadurismo que se resistía a abandonar el pasado, lo cierto es que toda esa doctrina constituye un testimonio de que las máximas de la experiencia necesitan orientaciones para el juez, que no deben darse por sabidas porque muchas veces no son conocidas ${ }^{10}$. A nuestro juicio este es un elemento esencial de la sana crítica que, por desgracia, Nieva no desarrolla.

En efecto, desde su origen la idea de la sana crítica se vinculó a un conjunto específico de reglas de buen juicio, especialmente referidas a la ponderación de la prueba testimonial. De alguna forma esas reglas de sana crítica estaban originalmente llamadas a precisar el concepto de sana crítica desde una perspectiva no formalizada (más allá de la tarifa legal) aunque, por desgracia, el proyecto y la intención no llegaran a buen puerto. A esta idea se llega por dos vías: la opinión de connotados juristas españoles de la época de la codificación de 1855, y la discusión de la Comisión de Codificación de la Ley de Enjuiciamiento Civil española de 1881. En uno y otro caso resulta claro que el concepto de sana crítica no pretendía ir más allá de las propias reglas de la sana crítica; aunque nadie hubiera reparado aún en ellas de manera sistemática ${ }^{11}$.

${ }^{10}$ Nieva, op. cit., p. 89.

${ }^{11}$ Rodrigo Coloma en su texto "Realmente Importa la Sana Crítica" se ha mostrado escéptico frente a la posibilidad de realizar un estudio sistemático de las reglas de Sana Crítica. Sin embargo, su crítica en tal sentido avanza en una dirección precisa y diversa a la que nos interesa en este momento. Coloma parece estar pensando en la posibilidad de una formulación científica de criterios racionales de ponderación indubitados y de aceptación general en la comunidad científica y jurídica. De ahí su remisión a los intentos de Bayer. Sin 
Con el tiempo las reglas de la sana crítica (de base jurídica) cayeron en el olvido y la idea de sana crítica como criterio y método de ponderación se independizó de esas reglas anclando sus bases en ideas más generales (principios de la lógica y máximas de la experiencia) que, como era de esperar, terminaron por borrar todos los contornos de la institución frente al sistema de la libre valoración de la prueba.

En lo que sigue de esta investigación mostraremos en qué medida la estrategia de vincular las reglas de la sana crítica a los principios de la lógica, las máximas de la experiencia y los conocimientos científicamente afianzados constituyó un error conceptual (sobre todo en lo que a la lógica toca) que clausuró, desde el inicio, la posibilidad de desarrollar una idea adecuada y autónoma del sistema; luego intentaremos mostrar en qué consistían algunas de esas primitivas reglas de la sana crítica que los juristas españoles del siglo XIX consideraban verdaderas máximas admonitorias. Luego veremos en qué sentido es posible diferenciar la orientación y contenido de las reglas de la sana crítica (recogidas, por ejemplo, en el texto Alfonsino) de los criterios y reglas racionales de ponderación de la prueba propios de la Freibeweiswürdigung. Finalmente, expondremos un concepto de sana crítica que, estructurado a partir de las reglas de buen criterio, no pierde su fisonomía propia frente a los sistemas de libre ponderación y de tarifa legal de la prueba.

\section{UNA CUESTIÓN DE CONCEPTOS: PRINCIPIOS, MÁXIMAS DE LA EXPERIENCIA Y EL ERROR DE LOS TEÓRICOS DE LA SANA CRÍTICA}

En los Segundos Analíticos (sobre la demostración), capítulo 10, Aristóteles realiza varias precisiones conceptuales en torno a las ideas de principio y demostración a partir de principios (mediante el seguimiento de reglas). En términos muy concisos define el filósofo el concepto de principio con las siguientes palabras: llamo principio en cada género a aquellos términos cuya existencia no puede demostrarse ${ }^{12}$. Luego añade, a modo ejemplar, que hay que admitir sin demostración lo que significan la unidad, la línea recta y el triángulo; es preciso admitir igualmente sin demostrarlo que la unidad y la magnitud existen; y solo para

embargo, por otra parte, no duda en calificar a los criterios de ponderación de Sana Crítica como verdaderas reglas de inferencia cuyo contenido va más allá de las razones epistemológicas. En este sentido escribe, "actuar conforme a las reglas de la SC lleva a jueces y abogados a situarse fuera de los test habituales para validar enunciados. Se hace necesario, entonces, repensar la manera de explicar los sistemas de valoración de la prueba, ya no enfatizando directamente el problema de la calidad epistémica de sus reglas, pues ello lleva a que las diferencias entre ellos se difuminen (nadie en sus sano juicio quiere ser tildado de irracional), sino recurriendo a otros enfoques" (Coloma, op. cit., pp. 768-769). Ahora bien, de acuerdo con Coloma las reglas de ponderación de Sana Crítica (SC) han de ser extraídas del extrarradio jurídico. "En el caso de la SC, la responsabilidad por lo que es señalado en las reglas de validación de 'hechos' se hace recaer en los cultores de disciplinas socialmente reconocidas en la producción de conocimientos” (Coloma, op. cit., p. 775). Pero la cuestión es, ¿no es posible encontrar, también, dentro de la tradición jurídica, reglas de buen criterio de ponderación de los hechos congeniales con la naturaleza de los procesos judiciales? A nosotros nos parece que sí, como veremos más adelante en esta investigación.

12 Aristóteles, Tratados de Lógica, Ed. Porrúa, México D.F., 2011, p. 229. 
lo demás tiene lugar la demostración ${ }^{13}$. Finalmente, en este punto, Aristóteles agrega que los principios pueden ser comunes, si han de servir para todas las ciencias, o especiales si solo se aplican a una (o algunas) de ellas.

Los principios de la lógica (identidad, no contradicción y tercero excluido), según refiere el propio Aristóteles, son principios comunes de naturaleza ontológica, esto es, susceptibles de ser aplicados a todo conocimiento científico (y, en general, a cualquier actividad intelectual coherentemente estructurada). En tal sentido no extraña que Aristóteles haya realizado la exposición de los mismos en el libro sobre la Metafísica y no en sus tratados de lógica. En la Metafísica, Libro IV, nos dice el filósofo que puesto que es obvio que tales principios pertenecen a todas las cosas, en tanto que cosas que son (esto, en efecto, es lo que tienen de común), su estudio corresponde también al que se ocupa en esclarecer lo que es, en tanto que es ${ }^{14}$.

Estos principios de naturaleza ontológica son los que permiten la interna coherencia del pensamiento. Aristóteles realiza la demostración de su tesis a partir de la exposición del principio de no contradicción y la forma en que este resuelve las aporías (de la no identidad). El principio de no contradicción es definido en los siguiente términos: es imposible que lo mismo se dé y no se dé en lo mismo a la vez y en el mismo sentido (y cuantas precisiones habríamos de añadir, dense por añadidas frente a las dificultades dialécticas $)^{15}$. Esta idea, que para Aristóteles es fundamental, se sustenta sobre el concepto de identidad como axioma indemostrable por su autoevidencia y se proyecta al principio de tercero excluido desde la premisa de la identidad absoluta que subyace a la no contradicción. Es decir, en la proposición disyuntiva de carácter exclusivo A es $\mathrm{A}$ o $-\mathrm{A}$, solo cabe ser verdadero A o $-\mathrm{A}$.

Ahora bien, a partir de tales principios es posible establecer reglas para el correcto entendimiento. Estas reglas, en la lógica aristotélica se proyectan desde las operaciones conceptuales hasta los razonamientos silogísticos, pasando por las operaciones proposicionales $^{16}$.

\footnotetext{
${ }^{13}$ Aristóteles, op. cit., p. 229.

${ }^{14}$ Aristóteles, Metafísica, Ed. Gredos, Madrid, 1994, p. 171 (1005a 25-30).

15 Aristóteles, Metafísica, op. cit., p. 173 (1005b 20).
}

16 Tomemos como ejemplo la regla de la distribución del predicado en el caso de las inferencias inmediatas por conversión simple. La regla en esta materia indica que se debe mantener en el predicado la misma cantidad (universal/particular), al momento de realizar una inferencia inmediata por conversión (cambio de sujeto a predicado). Así, en la proposición "ningún testigo miente"; el sujeto (ningún testigo) tiene naturaleza universal y al tratarse de una proposición negativa (su cualidad), tiene siempre predicado universal (ninguno miente). Si se realiza la inferencia inmediata de conversión, ésta ha de realizarse en términos simples, es decir, sólo basta cambiar el sujeto por el predicado: "ninguno que miente es testigo". Sin embargo, una cosa diversa ocurre si se intenta realizar la conversión con una proposición universal afirmativa. Por ejemplo, si decimos ahora que "todo testigo miente", el sujeto (todo testigo) es de naturaleza universal (lleva el cuantificador "todo"); pero el predicado es particular (esto es lo propio de toda proposición afirmativa), es decir, la proposición indica que la clase de los "mentirosos" es mayor a la de los testigos, con lo que además de ellos, pueden haber otros que mientan, con lo que la predicación de ser "mentiroso" todo testigo es siempre particular a la clase de los "testigos". De manera tal que, la proposición "todo testigo miente", convierte solo por accidente a "alguno que miente es testigo". Pues la regla indica que si es posible pasar 
Pues bien, a nuestro juicio, y en lo que a los principios de la lógica toca, el error de los teóricos de la sana crítica ha consistido en tomar una tríada de principios comunes del entendimiento humano (y más específicamente el de no contradicción), aplicables a toda actividad científica, como principios específicos de un método de ponderación. Lo común no puede servir de diferencia específica. Cuestión que, a la vez, ha redundado en una casi nula actividad científica en orden a determinar los principios específicos que subyacen a las reglas de la sana crítica que pudieran servir de guía a la actividad de ponderación de la prueba que realizan los magistrados ${ }^{17}$.

Otro tanto, por desgracia, se puede decir de las máximas de la experiencia. El concepto fue originalmente desarrollado por Fiedrich Stein ${ }^{18}$ para designar, de manera genérica, ciertos juicios (lógicos) de naturaleza hipotética, formulados a partir de generalizaciones empíricas, cuyo propósito es predecir la ocurrencia de hechos futuros ${ }^{19}$. Muy pronto las reflexiones de Stein fueron discutidas, ampliadas, corregidas y, finalmente, apropiadas por los procesalistas de inicios del siglo XX.

Couture al formular su concepto de "sana crítica", como tercera vía entre la prueba tasada y la libre, sin lugar a dudas toma de Stein la idea de máximas de la experiencia y de ahí en adelante, de manera invariable la sana crítica quedó ligada a este tipo de juicio (inductivo-hipotéticos) y a los principios de la lógica monotónica aristotélica (deductivo-apodícticos) $^{20}$.

Lo que resulta curioso de esta asociación es, por una parte, que el libro de Stein se inscribe en la tradición de la libre ponderación alemana, con lo que nuevamente resulta evidente el problema de la caracterización de la sana crítica a partir de un criterio compartido con otro sistema de valoración de la prueba. Por otra parte, y esto es aún más significativo, el propio Stein dedica un capítulo completo a lo que él denomina "las máximas de la experiencia legales". La verdad, dicho capítulo funciona como un epílogo a su precedente en el que Stein ya había advertido que algunas de las llamadas "máximas de la experiencia" constituyen un acervo jurídico compartido, tanto de los sistemas de libre ponderación como de los de prueba tasada, de los que, las más de las

\footnotetext{
de lo universal a lo particular, nunca lo será pasar de lo particular a lo universal. Para un estudio acabado y prolijo sobre la lógica menor aristotélica véase Maritain, J., El Orden de los Conceptos. Lógica, Editorial Club de Lectores, Buenos Aires, 1978. Especialmente confróntese con las páginas 192-198 en las que el autor realiza un estudio acerca de las reglas de la conversión.

${ }^{17}$ Para un estudio de la genealogía de la sana crítica judicial a partir de la obra de Aristóteles, véase Cuello Iriarte, Gustavo, La sana crítica. Sistema de valoración de la prueba judicial, Pontificia Universidad Javeriana, Bogotá, 1974.

18 Stein, F., El Conocimiento Privado del Juez, Ediciones Universidad de Navarra, Pamplona, 1973.

19 Son definiciones o juicios hipotéticos de contenido general, desligados de los hechos concretos que se juzgan en el proceso, procedentes de la experiencia, pero independientes de los casos particulares de cuya observación se han inducido y que, por encima de esos casos, pretenden tener validez para otros nuevos. Stein, op. cit., p. 30.

${ }^{20}$ Para un estudio de los inconvenientes de esta estrategia se puede consultar: Laso, J., "Lógica y sana crítica”, en Revista Chilena de Derecho, vol. 36, núm. 1, abril, 2009.
} 
veces, se extraen ${ }^{21}$. Finalmente, Stein se refiere a "estas máximas de la experiencia" recogidas en la ley como verdaderas máximas de la experiencia de oro ${ }^{22}$.

De forma muy probable también le debemos a Stein (o mejor dicho a la interpretación que de sus ideas se hizo) la idea de "conocimientos científicamente afianzados" (con lo que la doctrina de la sana crítica tradicional completó el concepto) como criterio coadyuvante en la ponderación de la prueba. En efecto, para Stein existe una relación necesaria entre el informe pericial (locus propio y técnico de las máximas de la experiencia) y los conocimientos científicos disponibles en un lugar y tiempo determinados; y es la posesión de dichos conocimientos lo que hace del perito un medio de prueba fungible, del que solo se espera ciertos conocimientos deseados ${ }^{23}$.

Además, respecto de las máximas de la experiencia como criterio de diferenciación del sistema de la sana crítica frente a los de libre ponderación y prueba tasada se pueden formular las mismas críticas que ya hemos realizado a propósito de los principios de la lógica. Es decir, estas ideas generales y comunes a prácticamente todos los sistemas de ponderación (por lo menos a todos los que pretenden una cierta coherencia interna y consistencia con la verdad) no sirven como diferencia específica de la sana crítica, con lo que insistir en ellas equivale a disolver la idea de sana crítica en el sistema de la libre valoración de la prueba ${ }^{24}$.

Pues bien, si se quiere seguir hablando de la sana crítica como un sistema diverso al de la libre ponderación y al de prueba tasada es necesario abandonar las ideas generales de la lógica y las máximas de la experiencia como categorías propias y específicas del sistema (conservando su calidad de género próximo) y retomar desde su origen las nociones más congeniales al mismo, a saber, las ideas de "reglas de la sana crítica”. Solo

21 Antiguamente, estas consideraciones y reflexiones estaban, en su mayor parte, reguladas legalmente. La teoría de la prueba legal sustituía la experiencia individual y la opinión del juez por ciertas "experiencias promedio" (Durchschnittserfahrungen) sobre el valor de los medios de prueba y si bien el derecho vigente ha ampliado sustancialmente el campo de discrecionalidad judicial, renunciando por completo a influir en la apreciación del juez, el valor interno de aquellas reglas, injustamente calumniadas en el movimiento de reforma, se ha cuidado, sin embargo de que, aun sin coacción, sigan aplicándose. Stein, op. cit., p. 46.

${ }^{22}$ Stein, op. cit., p. 46. Obviamente estas máximas de la experiencia "de carácter jurídico" no agotan el repertorio de los juicios hipotéticos condicionales de naturaleza inductiva que explican y ordenan la experiencia en términos generales, sino que han de entenderse incorporados a los mismos.

23 Stein, op. cit., p. 75.

${ }^{24}$ En la misma dirección se puede citar la opinión de Per Olof Ekelöf, quien señala, a propósito de las supuestas distinciones radicales entre el sistema de ponderación de la prueba libre y el sistema de tarifa legal, que "también, dentro de la doctrina de la prueba legal, la evaluación de la prueba se produce subsumiendo casos concretos en reglas generales. Es cierto que cuando esas reglas se encuentran en un estatuto, la evaluación de la prueba asume el carácter de una aplicación general de reglas". Ekelöf, P., "Free Evaluation of Evidence", Scandinavian Studies in Law, No 8, 1964, p. 50. Aún más, Ekelöf cuestiona en este trabajo que el sistema de libre ponderación de la prueba se diferencie del régimen de valuación tasada por el hecho de que el primero obligue al juez solo a fallar de acuerdo con la experiencia general (de parte de la verdad) mientras que el segundo lo conmine a ponderar de acuerdo con el estatuto. Lo cierto es que en ambos casos se le pide al juez que de manera razonada interprete los hechos de acuerdo con cierta frecuencia altamente probable. En la misma dirección avanza, aunque desde otro marco conceptual, la fundamental obra de Alex Stein, Foundations of evidence de 2005. 
obrando de este modo es posible advertir las peculiaridades del régimen de ponderación introducido en la legislación procesal española del siglo XIX y explicar, coherentemente, por qué razón nuestros jueces podrían ponderar la prueba de acuerdo con la sana crítica, sin necesidad de un conocimiento acabado de la lógica, las máximas de la experiencia y los conocimientos científicamente afianzados.

\section{LAS REGLAS DE LA SANA CRÍTICA. El ENSAYO DE LOS JURISTAS} ESPAÑoles DEL Siglo XIX, A PROPÓSito DEL ARTíCulo 317 DE LA LEY DE EnjuiCiamiento Civil

La Ley de Enjuiciamiento Civil española de 1855 introdujo por primera vez, en el ámbito procesal civil ${ }^{25}$, la idea de ponderar la prueba (especialmente la testimonial) de acuerdo con las reglas de la sana crítica. Su artículo 317 dispuso que: los jueces y tribunales apreciarán, según las reglas de la sana crítica, la fuerza probatoria de las declaraciones de los testigos; con lo que de manera expresa se liberó a los sentenciadores de la práctica bastante extendida de "contar" el número de las declaraciones más que atender a sus cualidades.

La estrategia legislativa fue bien recibida tanto por la doctrina como por la jurisprudencia de la época; aunque no siempre por las mismas razones. Pues, mientras la primera entendió, de forma mayoritaria, que la nobel institución tenía por finalidad desformalizar la ponderación de la prueba, entregando al juez y a los tribunales un margen de discreción congenial con el buen criterio y sentido común de las razones que habían inspirado al sistema tasado (especialmente las reglas de buen juicio contenidas en la Ley de Partidas); la segunda, por el contrario, equiparó sin más la idea de sana crítica a la de íntima convicción (al modo francés), pensando que de ahí en adelante los jueces y los tribunales gozaban de la más absoluta libertad para valorar la prueba testimonial ${ }^{26}$. Con

${ }^{25}$ Unos años antes, el artículo 148 del Reglamento acerca del modo de proceder el Consejo Real en los negocios contenciosos de la Administración había dispuesto que: Las demás personas serán examinadas como testigos, sin perjuicio de que las partes puedan proponer acerca de ellas, y el Consejo calificar según reglas de sana crítica, las circunstancias conducentes á corroborar ó disminuir la fuerza probatoria de sus declaraciones (Reglamento sobre el modo de proceder el Consejo Real en los negocios contenciosos de la Administración, Imprenta Nacional, Madrid, 1847).

${ }^{26}$ El Código de Instrucción Criminal Francés de 1808 dispuso en su artículo 342: "La loi ne demande pas compte aux jurés des moyens par lesquels ils se sont convaincus: elle ne leur prescrit point de règles desquelles ils doivent faire particulièrement dépendre la plénitude et la suffisance d'une preuve: elle leur prescrit de s'interroger eux-mêmes dans le silence et le recueillement, et de chercher dans la sincérité de leur conscience, quelle impression ont faite sur leur raison les preuves rapportées contre l'accusé, et les moyens de sa défense.

La loi ne leur dit point: Vous tiendrez pour vrai tout fait attestépar tel ou tel nombre de témoins; elle ne leur dit pas non plus: Vous ne regarderez pas connue suffisamment établie, toute preuve qui ne sera pas formée de tel procès-verbal, de telles pièces, de tant de témoins ou de tant d'indices; elle ne leur fait que cette seule question, qui renferme toute la mesure de leur devoir: Avez-vous une intime conviction? A su vez, esta disposición era tributaria de un conjunto de normas de la época revolucionaria (el Decreto de 16-29 de septiembre de 1791 y la Instrucción de 29 de septiembre-21 de octubre de 179) que había regulado la ritualidad que debía seguirse en lo referido a la recepción y evaluación de la prueba por jurados (véase Montero, J., "Valoración de la prueba, reglas legales, garantía y libertad en el proceso civil”, en Revista Iberoamericana de Derecho Procesal Garantista, 2007, pp. 2-23). A los jurados, antes de deliberar respecto de la prueba presenciada y ofrecida, se les leía el siguiente 
el tiempo fue esta la posición que adquirió más fuerza y la que propició la modificación legislativa de 1881 (artículo 659).

Con todo, lo que nos interesa en este momento es atender a las razones que esgrimieron algunos autores para sostener que la noción de reglas de la sana crítica, introducida en el artículo 317, simplemente buscaba extender los límites demasiado rígidos de las leyes de Partida (sobre todo en lo que al número de testigos se refería), sin renunciar necesariamente a los criterios propuestos por las Partidas que, a juicio de ellos, expresaban de buena manera reglas de prudencia y sana crítica.

En esta dirección, uno de estos autores expresa: A primera vista parece que este artículo haya introducido una reforma radical en nuestro antiguo derecho relativamente al valor y apreciación de la prueba de testigos; pero si se examinan y se comparan con él las leyes de Partida que tratan de esta materia, se verá que en la esencia no se ha becho novedad alguna... Aunque dichas leyes sancionaron el hecho de que dos testigos contestes y libres de toda excepción hacen plena prueba, también dejaron a la sana crítica del Juez la apreciación de la fuerza probatoria de sus dichos cuando estos son contradictorios ${ }^{27}$. Añade otro: Pues bien, la Ley de enjuiciamiento al determinar en el artículo 317 que los jueces aprecien las declaraciones de los testigos por las reglas de la sana crítica, ha avanzado mucho más que la ley de Partida: ha querido sin duda sancionar la misma doctrina, aunque con mayor claridad, y ordena a los jueces no se atengan al número de testigos para apreciar los méritos de credibilidad ${ }^{28}$. Y todavía un tercero: De las consideraciones que llevamos expuestas se deduce claramente, que las leyes de Partida al determinar reglas generales

texto, idéntico al citado artículo 342: "La ley no pide cuentas (a los jurados) de los medios por lo que se han formado una convicción; no les prescribe las reglas a las cuales deben atribuir en particular la plenitud y la suficiencia de una prueba; ella exige que se interroguen a sí mismos y en silencio y en recogimiento y que busquen determinar, en la sinceridad de su conciencia, qué impresión han causado en su razonamiento las pruebas aportadas contra el acusado y los medios de defensa (...). La ley les hace una sola pregunta, que compendia toda la medida de su deber: ¿tenéis una íntima convicción?”. Bonnier, a su vez, hace derivar esta norma de la Ley $7^{\circ}$, sec. $2^{\circ}$, D. de Testib. que dispuso en tiempos de Adriano: Quae argumenta et ad quem modum probando cuique rei sufficiant, nullo satis certo modo definire potest. Sicut non Semper, ita saepe sine publicis monumentis cujusque rei veritas auctoritas, alias vel uti consentiens fama, conformat rei, de qua quaeritur, fidem. Hoc ergo solum tibi rescribere possum summatim, non utique ad unam probationis speciem cognitionem statim alligari debere, sed ex sententia animi tui aestimare debere, quid aut credas aut parum probatum tibi opineris. Bonnier, E., Tratado de las Pruebas en Derecho Civil y en Derecho Penal, Editorial Reus, Madrid, 1913, p. 192. Es decir, la legislación francesa vino a rescatar la que fuera la máxima en el derecho romano imperial (la libre apreciación de la prueba); máxima que se mantendría en Europa hasta la baja Edad Media, con el advenimiento del sistema probatorio de derecho canónico. Aunque el Código de Procedimiento Civil Francés (Code de Procédure Civile) de 1806 no había dispuesto de manera expresa la adopción del sistema de la íntima convicción, muy pronto esta se transformó en la regla general de la práctica jurisdiccional y en objeto de estudio de los comentarios de la doctrina, haciéndose extensiva la idea de la íntima convicción ahora a los jueces profesionales en materia civil (Taruffo, op. cit., p. 136.). Así las cosas, la legislación gala de comienzos de XIX recogió en su proceso de codificación (jurisprudencia y doctrina) prácticamente todos los ideales ilustrados de la época. Como era de esperar, muy pronto los códigos napoleónicos sirvieron de modelo a las diferentes legislaturas europeas (véase a este respecto, Van Rhee, CH., "Evolución del derecho procesal civil en Europa: cómo el juez activo se convirtió en lo normal", en Revista Chilena de Derecho y Ciencia Política, vol. 2, No 2, 2011, p. 14).

${ }^{27}$ Manresa y Navarro, J. M. et al., Ley de Enjuiciamiento Civil Comentada y Explicada, Imprenta de la Revista de Legislación, Madrid, 1856, pp. 386-387.

${ }^{28}$ Hernández de la Rúa, V., Comentarios a la Ley de Enjuiciamiento Civil, Imprenta Boletín de Jurisprudencia, Madrid, 1856, p. 397. 
sobre la fuerza probatoria de las declaraciones de los testigos, se ajustaron á las que prescribe la sana crítica; de manera, que aun cuando se entendiesen derogadas por el art. 317 de la nueva ley las disposiciones de nuestros códigos anteriores que marcan el valor ó fuerza legal de la prueba de testigos, aun cuando no debieran considerarse vigentes, debieran seguirse y adoptarse como reglas fundadas en la crítica racional y en la buena lógica, como seguras guías mediadoras del arbitrio judicial y reguladoras de su criterio ${ }^{29}$.

Todos estos juristas comparten la idea de que las reglas de buen criterio contenidas en las Partidas conservan para el juez todo su valor como máximas de sano juicio. Lo que no se corresponde con las reglas de la sana crítica, por el contrario, es la práctica habitual de la época de "contar los testimonios" más que atender a su contenido o circunstancias. Es decir, el artículo 317, para estos autores, es un llamado de atención a los jueces y tribunales en orden a ponderar la prueba de acuerdo con un conjunto de reglas de sano juicio que han de primar por sobre la mera asignación formal de valor al medio probatorio (en este caso la prueba testimonial).

Las Partidas, en efecto, no solo regulaban la recepción de la prueba testimonial en atención al número de testigos, sino que establecían a su vez un conjunto de reglas de orientación racional para la ponderación de sus dichos. Entre estas disposiciones merecen especial mención las leyes $12^{\mathrm{a}}$ a $15^{\mathrm{a}}, 22^{\mathrm{a}}, 29^{\mathrm{a}}, 32^{\mathrm{a}}$ y $41^{\mathrm{a}}$ del título $16^{\circ}$ de la Partida $\mathrm{III}^{30}$, que dan reglas muy prudentes, que bien pueden ser consideradas como de sana crítica para apreciar la prueba de testigos, tasándola para casos determinados ${ }^{31}$. Y, por idéntica razón, no faltó quien se apresurará a dotar de contenido a la esquiva noción de reglas de la sana crítica indicando con claridad cuáles eran en definitiva. En pocas palabras, son reglas de sana crítica a propósito de la prueba testimonial: i) no creer los dichos de un solo testigo, aunque este sea imparcial y de buena fama, pues es fácil que uno solo se equivoque; ii) vale más el testimonio de dos o más testigos contestes, de buena fama y sin interés, que el testimonio de dos o más que no reúnen los antedichos requisitos; iii) el testimonio

${ }^{29}$ De Vicente y Caravantes, J., Tratado bistórico, critico filosófico de los procedimientos judiciales en materia civil, Imprenta de Gaspar y Roig, Madrid, 1856, p. 261.

${ }^{30}$ La ley 41 del título $16^{\circ}$ de la Partida III, merece una mención especial, pues ella resolvía con buen criterio la discrepancia entre testigos, al disponer que ligeramente podria acaecer, que los testigos de la vna parte aduxesse, que se desacordarian en sus dichos, de manera que los vnos dirian el contrarios de los otros. E porende dezimos, que cuando assi acaeciere, que el Juzgador deue creer a aquellos que semejare que se acuestan mas a la verdad, e que acuerdan mas con el fecho, maguer que los otros fuessen mas: e non deue empecer a la parte el testimonio contrario, que los otros ouiessen dicho. Como se observa, aquí el sentenciador debe evaluar el testimonio de acuerdo con la verdad de los hechos, aunque la parte mayoritaria de los testigos no hubiese depuesto en tal sentido (maguer que los otros fuessen mas), de donde la disposición presente viene a complementar a la ley 32 de la misma Partida.

${ }^{31}$ Manresa y Navarro, J., Comentarios a la Ley de Enjuiciamiento Civil Reformada, Instituto Editorial Reus, Madrid, 1955, p. 632. Así, la ley $8^{a}$ prescribía criterios para la ponderación de los dichos de testigos de mal carácter y pública mala reputación (testigos condenados por falso testimonio); las leyes $12^{\mathrm{a}}$ a $15^{\mathrm{a}}$ indicaban las razones de buen juicio para descartar los testimonios de parientes y siervos, por carecer de la imparcialidad necesaria en orden a alcanzar la verdad; la ley $22^{\text {a }}$ dudaba de la veracidad del testimonio prestado por el enemigo de una de las partes; la ley $29^{a}$ indicaba el tipo de preguntas que el juez debía hacer a los testigos en orden a determinar la veracidad de sus dichos, y la ley $41^{a}$ resolvía con buen criterio la equivalencia en número de testigos por cada parte. 
de dos o más testigos imparciales hará plena prueba cuando no se haya desvirtuado por otros medios probatorios; iv) si entre los testigos hay contradicción ha de estarse a los dichos de aquellos testigos que hayan sido coherentes y consistentes con sus dichos; v) si todos los testigos gozan de las mismas buenas cualidades, el juez ha de descartar la testimonial para ambas partes ${ }^{32}$. Además, a estas reglas muy concretas, hay que añadir todas aquellas que en la especie disponen las Partidas.

Es probable que de haber profundizado la doctrina en estas ideas, y de haberlas implementado en la práctica la jurisprudencia española, hoy la noción de sana crítica tendría un contenido bastante preciso no solo con relación a la prueba testimonial sino con todos los otros medios de prueba individual y conjuntamente considerados. Sin embargo, no fue este el caso. De hecho, primó el criterio de la jurisprudencia (que entendió que la ley le entregaba una suerte de libertad absoluta para ponderar la prueba testimonial). Y, aunque los problemas de esta interpretación rápidamente se hicieron sentir a propósito del recurso de casación, las modificaciones introducidas en la Nueva Ley de Enjuiciamiento Civil española de 1881 (artículo 659) no lograron revivir las ideas de aquella primera doctrina acerca de las reglas de la sana crítica ${ }^{33}$.

Llegados a este punto, alguien podría hacernos notar que, si bien es cierto que las reglas de la sana crítica, así como las hemos entendido, se apartan de forma bastante clara del sistema de prueba tasada o legal y del sistema de la íntima convicción francesa, no ocurre lo mismo con la propuesta alemana de la libre ponderación racional de la prueba que también está comprometida con la determinación de ciertos criterios objetivos de ponderación de la prueba. Si esto fuera así, los teóricos que hemos citado en la parte introductoria de esta investigación aún tendrían razón y valdría más concentrarse en los avances que a propósito de dicho sistema se han realizado en los últimos años.

Este argumento, con todo, no es del todo exacto. Por lo menos no lo es desde la perspectiva que a nosotros nos parece debiesen ser estudiadas las reglas de la sana crítica. Pues lo que resulta realmente interesante de estas (en el entendido de que ellas hunden su origen en el Código de las Partidas) es que se sustentan en algo más que la mera averiguación de los hechos. En ellas, en efecto, se recogen como criterios de ponderación pautas racionales de indagación de la verdad, criterios axiológicos generales y ciertos

32 Manresa y Navarro et al. op. cit., pp. 391-392.

33 Se sabe que a propósito de la discusión del artículo 659, a sugerencia de Manresa y Navarro (quien redactó la ley), se intentó introducir 6 reglas de sana crítica (probablemente idénticas a las que hemos incluido en el cuerpo de esta investigación) con ocasión de la prueba testimonial. Entre los pocos documentos que existen disponibles respecto de esta discusión está el siguiente: fue objeto de rectificación de la ponencia la valoración de la prueba testifical, artículo 317 de la Ley antigua, y la segunda propuesta de Manresa comprendía 6 casos o reglas de sana crítica, a la que se opuso terminantemente Acevedo-Presidente de la sala primera del Tribunal Supremo-, porque la valoración de la prueba en esta forma tendría implicaciones en la casación, que hasta abora no sujeta el criterio del tribunal más que a las reglas de la lógica, como no se exige a nadie para formar sus convicciones. En contra, opinaba Gutiérrez "que el recurso de casación pierde importancia si en él no se puede hablar de prueba". Fue decisivo el criterio de Alonso Martínez, porque la propuesta de Manresa convertiría la casación en tercera instancia, y redactó este de nuevo su ponencia, que corresponde con el actual artículo 659. Crónica de la Codificación Española 2, Procedimientos Civil, Ministerio de Justicia, Comisión General de Codificación, Madrid, 1972, pp. 143-144. 
valores jurídicos particulares congeniales con las anteriores ideas. En otras palabras, si se atiende, por ejemplo, a la regla v precedente, se advierte que dentro del juicio de "sana crítica" se incorporan las nociones de "imparcialidad", "buena fama", "coherencia", “consistencia” y "número". No todas ellas, está claro, se concentran en la verdad de los hechos (buena fama). Es más, la desactivación mutua de los testimonios (por equivalencia) obedece a un criterio de justicia más que a una cuestión epistemológica ${ }^{34}$.

Para demostrar lo anterior, veremos en nuestro siguiente apartado el diferente registro conceptual en que, desde sus orígenes, se desenvuelve la teoría de la Freibeweiswürdigung, como expresión de la tradición racional de la prueba libre con un marcado compromiso con la averiguación de la verdad de los hechos. Tomaremos como ejemplo, para estos fines, algunas de las reflexiones de Mittermeier, pues ellas, por lo menos temporalmente, coinciden con la discusión que a la sazón tenían los teóricos españoles respecto del sistema de la sana crítica.

\section{LOS CRITERIOS DE PONDERACIÓN DE LA FREIBEWEISWÜRDIGUNG COMO PAUTAS DE ORIENTACIÓN DIRIGIDAS AL JUEZ PARA ASEGURAR UNA VALORACIÓN RACIONAL DE LA PRUEBA CONFORME CON LA VERDAD DE LOS HECHOS}

Los territorios germanos no fueron ajenos al fenómeno del abandono de la prueba $\operatorname{tasada}^{35}$. Sin embargo, de alguna manera, las ideas ilustradas de carácter liberal que había

${ }^{34}$ La cuestión atinente al influjo extraepistemológico que reciben y suponen las reglas de recepción, diligenciamiento y, sobre todo, ponderación de la prueba, es algo que no ha pasado inadvertido para la teoría contemporánea de la prueba. En efecto, la compleja relación que surge en la fase probatoria jurisdiccional entre la averiguación de la verdad de los hechos y los compromisos axiológicos extraepistemológicos (anclados incluso en derechos y garantías constitucionales de las partes), sobre todo en los regímenes democráticoconstitucionales, han tornado inviable la tesis que afirma que la prueba jurisdiccional es una variación particular de la teoría general de la prueba en el ámbito de las ciencias naturales. En este contexto, algunos epistemólogos han desarrollado argumentos para superar el problema, mientras que otros teóricos de la prueba han visto en esta particularidad de la prueba judicial su más propia característica. Así, Larry Laudan, por ejemplo, reconoce que la fase probatoria judicial está influenciada por valores extraepistémicos que él, por cierto, en su calidad de científico, desaprueba. Al respecto escribe: he sugerido alternativas a esas reglas que podrían ser más favorables para la averiguación de la verdad sobre los hechos delictivos. Abora, al final de este largo experimento mental, debemos elegir entre esas reglas que promueven genuinamente la búsqueda de la verdad y sus homólogas que la obstaculizan. Si los valores epistémicos fuesen los únicos valores en juego, sería previsible la elección. Pero otros valores interfieren - desde los derechos que se atribuyen a las partes de un proceso penal hasta cuestiones de imagen pública y eficiencia-, por lo que deben tomarse decisiones difíciles (Laudan, Larry, Verdad, Error y Proceso Penal, Marcial Pons, Madrid, 2013, pp. 291-292). Alex Stein, por su parte, desde la perspectiva de la teoría de la prueba judicial va un poco más lejos y afirma que la concepción epistemológica de la prueba es no solo teóricamente errada, sino que está jurídica y políticamente desorientada. No se trata de que Stein niegue el componente epistemológico de la fase probatoria judicial como un elemento esencial de la misma, sin embargo, lo que afirma este autor es que dicho componente no es suficiente para explicar el fenómeno y las particularidades de la prueba judicial (vid. Stein, Alex, Foundations of Evidence, Oxford University Press, N.Y., 2005, especialmente el capítulo IV, pp. 107-140).

${ }^{35}$ Igual como había ocurrido en otras partes de Europa, los códigos napoleónicos llegaron al territorio alemán gracias a la ocupación militar. Sin embargo, no abandonaron estas regiones de la misma manera. 
constituido la esencia de la legislación francesa postrevolucionaria no penetraron con tanta fuerza en la cultura jurídica germana (tal vez precisamente porque se adoptaron lejos de un contexto revolucionario). En esta, aunque se inició una profunda reforma influenciada en buena medida por las ideas galas, hubo tiempo para reflexionar con mayor calma acerca del sentido y alcance de algunos de los cambios más significativos.

En este contexto, cuando los juristas de lengua alemana incorporaron la idea de libre ponderación de la prueba lo hicieron con matices diferentes a sus pares franceses. La intención fue adoptar un sistema de "ponderación racional”, es decir, uno en que el Juez debe pesar con justo criterio lógico el valor de las pruebas producidas, y puede tener por verdadero el hecho controvertido, solo sobre la base de las pruebas que excluyen toda duda de lo contrario. La verdad jurídica depende en el sistema no de la impresión, sino de la conciencia del Juez, que no puede juzgar simplemente, según su criterio individual, sino según las reglas de la verdad histórica, que debe fundamentar ${ }^{36}$.

En la ZPO de 1877 el sistema de la libre ponderación fue consagrado en el artículo $286^{37}$ que dispuso que el Tribunal teniendo en cuenta todos los elementos que hayan proporcionado las discusiones orales sobre el negocio y los resultados de la prueba que se haya ejecutado, resolverá según su libre convicción acerca de si debe tenerse por verdadera o no cada alegación de becho de las partes. En la sentencia se indicará los fundamentos y motivos de la convicción del Tribunal... Este no estará sujeto a reglas legales sobre la prueba más que en los casos señalados en esta ley.

A diferencia de lo que ocurre con la íntima convicción (en su versión referida a jurados populares ${ }^{38}$ ), la libre ponderación de la prueba alemana exige que el juez ex-

De hecho, por un buen tiempo algunas de las provincias allende al Rhin (ya no dominadas por Francia) mantuvieron en vigencia las leyes procesales francesas y cuando estas fueron derogadas formalmente, los respectivos códigos regionales las incorporaron en términos sustantivos. Tal vez el caso más interesante en esta dirección sea el Código de Hannover de 1850, que no solo se mantuvo muy próximo al Código de Procedimiento Civil Francés sino que además lo perfeccionó en muchos sentidos, erigiéndose en un digno sucesor del mismo. Por tanto no es una sorpresa que el Código de Hannover haya influenciado y sido consecuencia del siguiente Código Germano de Procedimiento Civil de 1877, esto es, la Reichszivilprozessordnung (ZPO). En algunos aspectos el Código de 1877 poseía una perspectiva aún más francesa que la de su predecesor hanoveriano; por ejemplo, un rasgo germano distintivo del Código hanoveriano, como es el Beweisinterlokut, no estaba presente en el Código Germano de 1877. No obstante, otros elementos del stock germano se mantuvieron, como las reglas sobre participación de terceros en el procedimiento. Por consiguiente, el procedimiento del Código Germano de 1877 puede ser calificado como una combinación de ideas francesas acerca del procedimiento civil y aquellas de la tradición jurídica común de los estados germanos (Vaan Rhee, op. cit., p. 20).

${ }^{36}$ Lessona, C., Teoría general de la Prueba en el Derecho Civil, Editorial Reus, Madrid, 1928, p. 355.

${ }^{37}$ El mismo principio se adoptó en el artículo 260 de la Ordenanza Procesal Penal alemana del mismo año (Die Strafprozessordnung o StPO).

${ }^{38}$ En Francia el sistema de la íntima convicción muy pronto se hizo extensivo a los jueces profesionales. Primero de forma explícita a los magistrados en sede criminal y luego a los jueces civiles (con el inconveniente de que en este caso muchas de las normas probatorias permanecieron en el Código Civil, código que indicaba legalmente el valor de ciertas pruebas). Y, cuando en 1873 Bonnier publica su famosos Tratado sobre las Pruebas también la doctrina francesa parece estar completamente de acuerdo en que el sistema de la íntima convicción supone una base racional de ponderación que ha de sujetarse a un conjunto bien definido de principios. De hecho, toda la primera parte del libro de Bonnier está dedicada a exponer los principios que inspiran al derecho procesal galo, tanto en materia civil como criminal, indicando con precesión las estrategias que el juez puede adoptar para alcanzar la verdad. Para Bonnier la verdad se hace manifiesta ya por la evidencia 
plícitamente haga saber a las partes y a la comunidad los fundamentos y motivos que lo han llevado a valorar la prueba rendida en una dirección determinada. Goldschmitd, comentando la opción legislativa de la ZPO, realiza algunas importantes aclaraciones. En primer lugar, la última parte de la norma (que en el texto original constituye su inciso segundo) no debe entenderse como una remisión a ciertas reglas legales de ponderación, sino exclusivamente a las reglas concernientes a recepción y exclusión legal de ciertas pruebas. Estas reglas probatorias, por una parte, hacen que el sistema establecido en la ZPO sea de carácter mixto (en el sentido de que existen en él ciertas normas que limitan la libre valoración de la prueba) y, por otra, señalan las condiciones de apreciación de la prueba dentro de los límites propios de un procedimiento inmediato y oral. En segundo lugar, el fin de la prueba en este contexto es lograr el convencimiento racional del juez dentro de un proceso judicial. Siendo la verdad que se persigue solo relativa, es decir, simple verosimilitud, debe sustituirse el patrón objetivo para apreciarla por uno subjetivo: el convencimiento del juez. El artículo 286 de la ZPO ha resuelto fundamentalmente en sentido negativo, dejando a salvo las excepciones, las cuestiones suscitadas a este propósito, de si la ley debe sujetar al juez a sus disposiciones en la formación de su convencimiento; es decir, se ba pronunciado en el sentido de la libre apreciación de la prueba por el juez ${ }^{39}$.

Ahora bien, más allá de consagrar un sistema de prueba libre, la exigencia establecida en la ZPO de 1877 en orden a exigir del juez una fundamentación y justificación de su valoración de la prueba de inmediato trajo como consecuencia la necesidad de proveer a los tribunales de "insumos" adecuados para lograr tal cometido. En este sentido, Mittermeier nos ofrece un buen ejemplo de la forma en que la doctrina alemana enfrentó este desafío.

La reflexión de Mittermeier es incluso anterior a la entrada en vigencia de los códigos unificados de Alemania; y tiene como punto de partida la recepción del sistema de libre ponderación de la prueba establecido en el Código de Instrucción Criminal francés de 1806 que ya había comenzado a ejercer una gran influencia en suelo alemán (especialmente respecto de un conjunto de proyectos presentados en la primera mitad del siglo XIX: el Proyecto de Ley para Wurtemberg, el Proyecto sobre Ley Criminal de Hannover y el Nuevo Proyecto de Código Criminal para Bavaria, entre otros). Por lo mismo, sus reflexiones se pueden considerar relevantes para nuestra investigación, toda vez que Mittermeier es un testigo privilegiado del cambio de paradigma en materia probatoria advirtiendo también los desafíos y riesgos que el nuevo modelo conlleva.

Mittermeier, luego de examinar en su Tratado sobre las Pruebas Criminales las desventajas del sistema de ponderación de la íntima convicción, dedica el capítulo XV (de las fuentes de la certeza) a exponer algunas ideas rectoras que el juez ha de considerar para alcanzar la certeza de los hechos probados.

ya por la deducción lógica ya por la inducción. Y dependiendo de la mayor o menor cercanía del medio probatorio con cada una de estas circunstancias mayor o menor será su fuerza. Asimismo, Bonnier no escatima esfuerzos en mostrar la forma cómo la lógica deductiva e inductiva han de ser aplicadas; y en qué casos no ha de desconocerse ni siquiera el valor de ciertas reglas legales. Véase Bonnier, op. cit., pp. 5-76; 194-195.

${ }^{39}$ Goldschmitd, J., Derecho Procesal Civil, Editorial Labor, Barcelona, 1936, p. 256. 
Mittermeier afirma que la teoría de la prueba se vincula con la verdad de los hechos. En tal sentido, existen dos aproximaciones posibles a los hechos: la percepción que de ellos tenemos por nuestros sentidos y la evidencia material de los mismos. En realidad, la primera es posible en virtud de la segunda. A su vez, la percepción de los hechos está, en principio, igualmente distribuida como capacidad en todos los hombres. En tal sentido, el informe pericial y la deposición testimonial pueden equipararse a la inspección personal del tribunal. Sin embargo, para que estas percepciones puedan producir la certeza es necesario que sean reguladas por la razón y sus criterios de validación. En este juego entre las percepciones, el hecho material y los criterios de la razón surge la idea de indicio como un elemento mediato de convicción. Al igual que Bonnier, las ideas precedentes sirven a Mittermeier para justificar una clasificación de los medios probatorios de acuerdo con su aptitud para producir la certeza del sentenciador (hecho material, inspección personal, informe pericial, confesión, testimonial y presunciones).

Para Mittermeier no hay certeza posible sin la mediación de la razón (sin importar el medio de prueba de que se trate). Y, en tal dirección, propone un conjunto de estrategias que han de ser consideradas por el juez al momento de evaluar la prueba. Se trata de 5 reglas de apreciación de la prueba que permiten justificar la convicción de juez:

1.- La conclusión de lo posible a lo real. La prueba rendida en autos debe estar en concordancia con la naturaleza de las cosas, es decir, los hechos han de interpretarse como ordinariamente se estima que ocurren. Por ejemplo, normalmente un hombre joven tiene más fuerza y energía que un anciano, y aunque es posible que se dé la situación contraria, los testimonios que así lo declaren estarán en mejor posición que sus contradictorios.

2.- La conclusión por analogía. En situaciones similares es normal que se produzcan similares resultados. Por ejemplo, si muchas personas asesinadas en una misma ciudad en un espacio determinado de tiempo exhiben en sus cuerpos idénticas lesiones en lugar y forma, es posible pensar que se trata del mismo o los mismos asesinos.

3.- La conclusión circunstancial del hecho principal. No solo importa el hecho principal (el delito mismo) sino la forma en que este se ha realizado. Una casa ha sido robada y no se ha forzado ninguna cerradura. Estas habían sido cambiadas una semana antes por un cerrajero de la ciudad. El cerrajero, a su vez, ha contratado hace un mes un ayudante que tiene un amplio prontuario criminal de robo en casas. La recta razón indica que es bastante posible que el ayudante del cerrajero esté involucrado en el robo.

4.- La conclusión posible y verosímil de la prueba testimonial. La razón indica que el testigo digno de crédito es aquel que pudo presenciar los hechos y tiene la voluntad de decir la verdad. Esta última se prueba por la concordancia de sus declaraciones con el hecho material, la interna coherencia de la misma y su consistencia con otros testimonios.

5.- La única conclusión posible a partir de los indicios. Tratándose de indicios estos deben ser graves, precisos y concordantes, pero además, no deben (por lo menos 
en materia criminal) admitir otras explicaciones. En el caso contrario, el tribunal habrá de indagar si las otras explicaciones en competencia con la principal inculpatoria son posibles. De serlo, habrá que aceptar la interpretación que propone la parte inculpada. Por ejemplo, se ha cometido un homicidio y junto al cadáver se halla un teléfono móvil. Al dueño del teléfono le asiste la posibilidad de proponer un conjunto de hipótesis que justifican o explican la presencia del objeto en el lugar del crimen (se lo habían robado tiempo atrás; lo había perdido; se lo había prestado a la víctima, etc.).

Obviamente no se trata de una enumeración taxativa de reglas críticas en materia probatoria (de hecho, es posible encontrar otras a propósito del análisis de los medios de prueba en particular); pero claramente funcionan como elementos de juicio que ha de tener en consideración el sentenciador al momento de evaluar la prueba rendida ya de forma individual o colectivamente considerada. Así, las verdaderas bases de la certeza son la confianza a la vez en la fidelidad de nuestros sentidos y en la fuerza del razonamiento que, tomando por punto de comparación las experiencias anteriores, somete a ella, como a una medida cierta, los hechos cuya realidad aprecia ${ }^{40}$.

Pues bien, de lo que venimos diciendo es posible colegir algunas consecuencias. En primer lugar, tanto el legislador alemán como la doctrina que acompaña a la discusión de la ZPO y la StPO de 1877 vieron con muy buenos ojos la adopción del sistema de la libre ponderación de la prueba. En segundo lugar, la recepción del nuevo sistema fue crítica y gradual, lo que permitió limitar las consecuencias negativas que mostraba la íntima convicción francesa. En este sentido, se mantuvieron en las leyes procesales alemanas algunas "reglas de la prueba" referidas al valor probatorio de ciertos medios de prueba y a las reglas de oportunidad, pertinencia y relevancia de la prueba, entre otras. El abandono del régimen de tarifa legal, en tercer lugar, muy pronto suscitó la necesidad científica de suministrar elementos de juicio a los magistrados para que ellos pudieran, por una parte, satisfacer las exigencias de fundamentación y justificación de sus fallos (y en especial de la valuación de la prueba) y, por otra, de poner a disposición de la comunidad las reglas y principios en juego en el proceso de ponderación (para así poder controlar también la racionalidad del fallo). Trabajos como los de Mittermeier y Stein (solo por citar dos) sirvieron, en cuarto lugar, para clarificar, dentro de un registro de base epistemológica, el sentido y alcance del abandono de las reglas probatorias (tarifa legal), mostrando que algunas de estas más allá de su derogación formal seguían vigentes por su autoridad racional. Finalmente, queda claro que dentro del horizonte alemán nunca ha sido suficiente señalar que la Freibeweiswürdigung se satisface simplemente por la apelación a la fórmula vacía de los principios de la lógica, las máximas de la experiencia y los conocimientos científicamente afianzados, sino que todas estas ideas están llamadas a ser llenadas de contenido por la ciencia del derecho y sus disciplinas coadyuvantes.

${ }^{40}$ Mittermeier, op. cit., pp. 121-122. 


\section{LA LIBRE PONDERACIÓN RACIONAL DE LA PRUEBA Y LAS REGLAS DE LA SANA CRÍTICA CASTELLANA: ALGUNAS DIFERENCIAS Y UNA NUEVA DEFINICIÓN DE SANA CRÍTICA A PARTIR DE LAS REGLAS DE SANA CRÍTICA}

Si se insiste, como se ha hecho hasta el momento, en sostener que las ideas constitutivas de la sana crítica son los principios de la lógica, las máximas de la experiencia y los conocimientos científicamente afianzados, cuyo valor epistémico se deriva de la posibilidad de aprehender con verdad los hechos del proceso judicial, los críticos de la sana crítica llevan toda la razón. Es decir, la sana crítica simplemente sería la expresión castellana de la Freibeweiswürdigung alemana, de la que habría extraído todas sus ideas. Por cierto, esta afirmación haría necesario un trabajo científico similar a los realizados por los grandes procesalistas alemanes de los siglos XIX y XX, con el fin de tornar realmente operativa la idea (cuestión que, de momento, por lo menos en nuestro medio, se ha realizado solo de manera incipiente ${ }^{41}$ ). Por el contrario, si se quiere afirmar que la sana crítica es un sistema de ponderación diverso (esa tercera vía, ahora, entre la Freibeweiswürdigung y la prueba tasada) ha de suministrarse los elementos teóricos en los que se sustenta esta posición.

Pues bien, cuando se mira de cerca la intención y el desarrollo que tuvo en sus inicios el sistema alemán y el español es posible advertir algunas diferencias que podrían, a su vez, explicar las particularidades de los dos sistemas (libre ponderación racional y reglas de la sana crítica), aunque los mantendrían, por cierto, dentro de una misma familia.

${ }^{41}$ Dos de los últimos trabajos de Rodrigo Coloma y Claudio Agüero han comenzado a transitar este camino. Se trata de "Lógica, ciencia y experiencia en la valoración de la prueba" (en Revista Chilena de Derecho, vol. 41, N 2, 2014, pp. 673-703) y "Fragmentos de un Imaginario Judicial de la Sana Crítica" (en Revista Ius et Praxis, año 20, No 2, 2014, pp. 375-414). Ambos trabajos, aunque en registros conceptuales diversos, avanzan en la idea de lo que ellos denominan "las promesas incumplidas de la sana crítica". De acuerdo con estos autores, uno de los grandes problemas de la idea de "sana crítica" y de las "reglas de sana crítica" es la insuficiente determinación conceptual (no en cuanto convención lingüística sobre la definición) de las ideas que integran el concepto con el fin de tornarlo operativo en los procesos de toma y control de las decisiones jurisdiccionales. Para efectos del presente trabajo, nos parece interesante hacer notar que en el texto acerca de Lógica, Ciencia y Experiencia en la Valoración de la Prueba, Coloma y Agüero advierten, con ocasión de las máximas de la experiencia que su sentido es posibilitar el "uso de conocimientos que surgen a partir de las vivencias de quienes pertenecen a la misma cultura. Es decir, a partir de cómo los miembros de una comunidad interpretan ciertos acontecimientos de la vida social. Ocurre que cuando los miembros de una comunidad sincretizan prácticas sociales por la influencia de otros grupos, la cultura se vuelve porosa y, entonces, las directrices que se infieren a partir de las experiencias sociales comienzan también a adquirir porosidad y pluralidad" (Op.cit., p. 678). En este sentido, las máximas de la experiencia adquieren un componente extraepistémico que está permeado por valores, creencias y prácticas culturales. Tal vez por esta razón en Fragmentos de un Imaginario Judicial los autores interrogando a un conjunto de jueces adviertan que, en lo que se refiere a las máximas de la experiencia, la comunidad jurídica de los jueces es tributaria de un cierto Ethos judicial del que no siempre está del todo consciente (vid., Fragmentos de un Imaginario Judicial de la Sana Crítica, Op. cit., p. 394). 
La libre ponderación racional de la prueba alemana parte de un principio general: la búsqueda de la verdad material ${ }^{42}$ por los medios probatorios y de los indicios. Para satisfacer esta idea, la legislación alemana le impuso al juez el deber de fundamentar y justificar su decisión; cuestión que, como hemos visto, llevó a su vez a la doctrina a elaborar una teoría científica de la prueba.

En la teoría científica de la prueba los procesalistas alemanes no descuidaron ningún elemento. Reflexionaron respecto de la organización judicial, los procedimientos y las condiciones para dar pronto y oportuno cumplimiento a la justicia. En este contexto, y en lo que a la teoría de la prueba toca, dos elementos recibieron una especial atención: la figura del juez y las estrategias y argumentos susceptibles de dilucidar toda duda razonable a propósito de sus fallos. En este sentido, las condiciones personales para el ejercicio de la función jurisdiccional fueron elevadas a la categoría de cualidades personales del magistrado, tanto de carácter intelectual como moral. No es de extrañar, por tanto, que autores de renombre de aquella época como Hanns Gross hayan dedicado una buena cantidad de páginas a este tema y muy especialmente al tipo de instrucción que ha de recibir un juez para poder fundamentar y justificar racionalmente su decisión ${ }^{43}$. El propio Stein, que se burla un tanto de Gross, hace lo propio al sostener que el juez debe disponer, pues, de todo el tesoro de la experiencia humana no jurídica para poder llevar a cabo cumplidamente la subsunción -stricto sensu-del supuesto de hecho en los conceptos jurídicos ${ }^{44}$.

En este sentido, los jurisconsultos alemanes advirtieron muy pronto que el sistema de libre ponderación racional de la prueba requiere jueces experimentados cuyos conocimientos son, las más de las veces, exorbitantes al derecho mismo (aunque este también lo deben conocer como ninguno).

También se dieron cuenta que en un sistema de libre ponderación es indispensable para el juez contar con algunas guías racionales que vayan más allá de la mera coherencia

42 Aunque la distinción entre "verdad material” y "verdad formal" ha recibido, desde hace algunos años, una abundante crítica, hemos decidido mantenerla en este artículo debido principalmente a que en un proceso judicial la búsqueda de la verdad se ve condicionada por la necesidad de resolver el conflicto entre las partes o entre una parte (imputado) y la sociedad; por satisfacer criterios más generales de justicia (asociados a los derechos de los intervinientes); por la determinación de las pruebas admisibles y pertinentes y por una larga lista de otros factores que sin carecer de racionalidad práctica difícilmente pueden ser comprendidos desde una perspectiva meramente epistemológica. Acerca del renovado interés de la doctrina en la diferenciación entre una verdad formal y una material, véase Summers, Robert S., "Formal Legal Truth and Substantive Truth in Judicial Fact-Finding -their Justified Divergence in Some Particular Cases", en Cornell Law Faculty Publications. Paper 1186, 1999.

43 "La cultura doctrinal del juez de instrucción ha de ser muy vasta, abarcando conocimientos de distinta índole: así, por ejemplo, deberá ser versado en el conocimiento de idiomas, para no valerse de intérpretes cuando interrogue a delincuentes extranjeros; ha de tener conocimientos de dibujo lineal y topográfico, para hacer por sí mismo los croquis y planos del lugar del suceso, o al menos apreciar debidamente los que hicieren los peritos; necesita conocimientos de medicina legal, para dirigir a los médicos forenses las preguntas que conduzcan al esclarecimiento de la verdad, no permitiéndoles extenderse en divagaciones inútiles, y apreciar debidamente sus informes...”. Gross, H., Manual del Juez, La España Moderna, Madrid, 1900, p. 17. Véase también concerniente a los requisitos de la educación del Juez instructor, pp. 19-23.

${ }^{44}$ Stein, op. cit., p. 60. 
lógica o la intuición personal. De ahí la necesidad de una reflexión científica en torno a las máximas de la experiencia como insumos indispensables de los argumentos forenses.

Por todas estas razones, la Freibeweiswürdigung terminó integrándose de forma armónica en unos códigos moderados que combinaron de manera prudente algunas de las reglas de recepción y ponderación de la prueba, contenidas en la tradición, con un margen considerable de discrecionalidad judicial.

Nada de esto, por el contrario, ocurrió en el caso español a propósito de la incorporación de la idea de reglas de la sana crítica. La Ley de Enjuiciamiento Civil de 1855 no estableció un principio general de ponderación de la prueba. De hecho, simplemente recogió las normas contenidas en la Ley de Partidas, a excepción del artículo 317 que consagró la idea de sana crítica. Pero, como hemos visto, aunque la doctrina y la jurisprudencia vieron con muy buenos ojos la adopción de la institución, muy pronto quedó de manifiesto que ellas no estaban entendiendo lo mismo.

Hasta aquí, como se aprecia, las ideas de los principios de la lógica, las máximas de la experiencia y los conocimientos científicamente afianzados son totalmente desconocidos en el contexto español. Es más, en la propia reforma de 1881 estas ideas no son siquiera discutidas en la Comisión de Codificación, limitándose ahora la controversia a la conveniencia o no de introducir un número clausus de reglas de sana crítica a propósito de la prueba testimonial (derivadas todas ellas, claro está, de las propias Partidas).

Sin embargo, nos parece que existe, por lo menos en la doctrina española del siglo XIX, una constante a propósito de la reflexión pertinente a la sana crítica. Esta constante es precisamente que existen un conjunto de reglas admonitorias de carácter jurídico llamadas a regular la actividad de ponderación de la prueba por parte del juez.

A diferencia del sistema alemán, en el que los juristas intentan dilucidar científicamente un conjunto de reglas para satisfacer las exigencias de fundamentación y justificación racional, en el modelo español de las reglas de la sana crítica se advierte un intento por rescatar ciertas máximas admonitorias que han de servir de guía al juez en la ponderación de la prueba dentro de un horizonte exorbitante a la mera averiguación de la verdad material de los hechos. Por consiguiente, ni siquiera se trata de verdaderas máximas de la experiencia (al modo en que, en términos generales, las entiende Stein, es decir, como juicios inductivos que permiten unas generalizaciones empíricas), sino de reglas, generalmente reconocidas en el derecho (Ley de Partidas), que aseguran a quien las sigue una grado no menor de prudencia práctica (bajo determinadas circunstancias). El valor de estas reglas no proviene, claro está, del hecho de haber sido consagradas en el texto de Alfonso X, sino que dicho cuerpo legal tuvo el mérito de haber recogido y sistematizado un conjunto de reglas racionales de ponderación de la prueba judicial congeniales con el entendimiento práctico de la época y la tradición jurídica romano-canónica.

El problema es, como Nieva lo advierte, que muchas veces estas máximas admonitorias son olvidadas o, incluso, nunca han sido aprendidas. De ahí el interés que tuvo esa primera doctrina española de las reglas de la sana crítica en rescatarlas como argumentos para la decisión judicial que, si bien ya no obligaban al juez a seguirlas de manera acrítica, sí le imponían el deber de fundamentar y justificar el porqué se apartaba de ellas en un caso particular. 
Es precisamente esta particularidad del sistema español de la sana crítica la que, nos parece, podría constituir su verdadera novedad. Así, la ponderación conforme con las reglas de la sana crítica, de acuerdo con la lectura que hemos propuesto, podría conceptualizarse como un método de ponderación de la prueba judicial que consiste en valorar la prueba rendida en autos conforme con un conjunto de reglas contenidas de forma explícita o implícita en la propia tradición de la legislación, doctrina y jurisprudencia probatoria, facultando al juez, previa justificación y fundamentación, para preferir unas en desmedro de otras o, incluso, en ciertos casos y circunstancias para abandonarlas del todo.

Eso sí, tanto la especificidad del método como su importancia práctica, de aceptarse el concepto que proponemos, pasa necesariamente por una re-construcción dogmática y jurídica de las reglas específicas de la sana crítica que, debidamente moduladas por los principios de derecho sustantivo que informen al procedimiento en cuestión, han de servir tanto de guía al juez como de criterios de control de la racionalidad del fallo para las partes en un lugar y tiempo determinados.

\section{BiBLIOGRAFÍA}

\section{Doctrina}

Aristóteles, Tratados de lógica, Ed. Porrúa, México D.F., 2011.

Aristóteles, Metafísica, Ed. Gredos, Madrid, 1994.

Bonnier, Eduardo, Tratado de las pruebas en derecho civil y en derecho penal, Ed. Reus, Madrid, 1913.

Cerda San Martín, Rodrigo, Valoración de la prueba. Sana crítica, Librotecnia, Santiago, 2008.

Coloma Correa, Rodrigo, "La caída del argumento de autoridad y el ascenso de la sana crítica", en Revista de Derecho (Valdivia), Vol. XXV, No 2, 2012.

Coloma Correa, Rodrigo, "Realmente importa la sana crítica", en Revista Chilena de Derecho, Vol. 39, No 3, 2012.

Coloma, Rodrigo y Agüero, Claudio, "Fragmento de un imaginario judicial de la sana crítica", en Ius et Praxis, 20, N 2, 2014.

Coloma, Rodrigo y Agüero, Claudio, "Lógica, ciencia y experiencia en la valoración de la prueba", en Revista Chilena de Derecho, Vol. 41, N 2, 2014.

Couture, Eduardo, Fundamentos del derecho procesal civil, Tercera Edición, Roque de Palma editor, Buenos Aires, 1958.

Cuello Iriarte, Gustavo, La sana crítica. Sistema de valoración de la prueba judicial, Pontificia Universidad Javeriana, Bogotá, 1974.

De Vicente y Caravantes, José, Tratado histórico, critico filosófico de los procedimientos judiciales en materia civil Tomo II, Imprenta de Gaspar y Roig, Madrid, 1856.

EkelöF, Per, "Free evaluation of evidence", en Scandinavian Studies in Law, No 8, 1964.

Goldschmitd, James, Derecho procesal civil, Ed. Labor, Barcelona, 1936.

Gorphe, Francois, La crítica del testimonio, Instituto Editorial Reus, Madrid, 1940.

Hernández de la Rúa, Vicente, Comentarios a la ley de enjuiciamiento civil, Imprenta Boletín de Jurisprudencia, Madrid, 1856.

García, Lyda y Acuña, Máximo, "Elementos de la sana crítica en el proceso civil", en Justicia, $\mathrm{N}^{\circ} 26$, diciembre 2014.

Gross, Hanns, Manual del juez, La España Moderna, Madrid, 1900. 
Laso, J., "Lógica y sana crítica”, en Revista Chilena de Derecho, vol. 36, núm. 1, abril, 2009.

Laudan, Larry, Verdad, Error y Proceso Penal, Marcial Pons, Madrid, 2013.

LePIN Molina, Cristian, "Breve estudio sobre la sana crítica”, en Gaceta Jurídica, No 319, 2007.

Lessona, Carlos, Teoría general de la prueba en el derecho civil, Ed. Reus, Madrid, 1928.

López Díaz, Carlos, "Apreciación de la prueba por la sana crítica y procedencia del recurso de casación en el fondo en los procesos ante los tribunales de familia”, en Gaceta Jurídica, No $294,2004$.

MANRESA y Navarro, José María - Miquel, Ignacio - Reus, José, Ley de enjuiciamiento civil comentada y explicada Tomo II, Imprenta de la Revista de Legislación, Madrid, ,1856.

Manresa y Navarro, José María, Comentarios a la ley de enjuiciamiento civil reformada Tomo III, Instituto Editorial Reus, Madrid, 1955.

Maritain, Jacques, El orden de los conceptos. Lógica, Ed. Club de Lectores, Buenos Aires, 1978.

Maturana, Javier, Sana crítica: un sistema de valoración racional de la prueba, Thomson Reuters, Santiago, 2014.

Mittermeier, C. J. A., Tratado de la prueba en materia criminal, $2^{a}$ edición, Revista de Legislación, Madrid, 1837.

Montero Aroca, Juan, "Valoración de la prueba, reglas legales, garantía y libertad en el proceso civil”, en Revista Iberoamericana de Derecho Procesal Garantista, número 2, 2007.

Nieva, Jordi, La valoración de la prueba, Marcial Pons, Madrid, 2010.

Rosemberg, Leo, Derecho procesal civil Tomo II, Ediciones Jurídicas Europa-América, Buenos Aires, 1955.

STEIN, Alex, Foundations of evidence, Oxford University Press, 2005.

STEIN, Fiedrich, El conocimiento privado del juez, Ediciones Universidad de Navarra, Pamplona, 1973.

Summers, Robert S., "Formal Legal Truth and Substantive Truth in Judicial Fact-Finding -their Justified Divergence in Some Particular Cases", en Cornell Law Faculty Publications. Paper 1186, 1999.

TAruffo, Michele, La prueba, Marcial Pons, Buenos Aires, 2008.

VALENTín, Gabriel, "La prueba y la sentencia: algunas reflexiones sobre la regla de la carga de la prueba”, en Revista de Derecho, Segunda época, Año 9. № 10, diciembre 2014.

VAN Rhee, $\mathrm{CH}$., "Evolución del derecho procesal civil en Europa: cómo el juez activo se convirtió en lo normal", en revista chilena de derecho y ciencia política, vol. 2, $\mathrm{N}^{\circ} 2,2011$.

VÁzQuez, José, "Los principios del proceso civil, en Responsa Iurisperitorum Digesta, Eduardo A. Fabián Caparrón editor, Ediciones Universidad de Salamanca, Salamanca, 2000.

\section{Legislación}

LEY de Enjuiciamiento Civil Española, 1855.

LEY de Enjuiciamiento Civil Española, 1881.

Código de Procedimiento Civil Francés (Code de Procédure Civile), 1806.

Código de Instrucción Criminal Francés (Coded'instrucción criminelle), 1808.

CóDigo de Procedimiento Civil Alemán, (Reichszivilprozessordnung), 1877.

OrdenanZa Procesal Penal alemana (Die Strafprozessordnung), 1877.

\section{Textos oficiales}

CrónICA de la Codificación Española 2, Procedimientos Civil, Ministerio de Justicia, Comisión General de Codificación, Madrid, 1972. 
